\title{
PERSISTÊNCIA E LIXIVIAÇÃO DO HERBICIDA SIMAZINA EM SOLO BARRENTO CULTIVADO COM MILHO ${ }^{1}$
}

\author{
FLÁVIO M. G. BLANCO², HÉLIO G. BLANCO³ e THAIS. R. MACHADO ${ }^{4}$
}

\section{RESUMO}

Foram determinadas, em experimento de campo, a persistência e a lixiviação do herbicida simazina na dose de $3 \mathrm{~kg} /$ ha i.a. em um solo pod zol vermelho-ama relo de textura barrenta plantado com milho, por meio do monitoramento de seus resíduos, durante um ano após a sua aplicação, em 14 de janeiro de 1992. 0 experimento foi conduzido na Estação Experimental do Instituto Biológico, Campinas, SP, utilizando-se o mét odo de cromatografia gasosa para a determinação analítica de resíduos. Empreg ou -se o fatorial 8 X 5, "é pocas de amostragem do solo" X "profundidades de a mostrage m", quatro repetições para os procedimentos experimentais no campo, reduzidas para duas nas determinações analíticas. Os resultados demonstraram que a maior concentração do herbicida localizou-se na camada supe rficial do solo (0-10 cm de profundidade), onde persistiu até 360 dias após o tratamento na concentração de $0,08 \mathrm{mg} / \mathrm{kg}$ de solo. A curva de persistência do produto, para a profundidade de $010 \mathrm{~cm}$, foi representada por uma equação exponencial do terceiro grau. Foram encontrados resíduos de simazina nas camadas de solo à profundidades de 10-20, 20-30 e 30-40 $\mathrm{cm}$ até 183,65 e 65 dias após o tratamento, respectivamente.

Palavras chave: Resíduo, solo, herbicida, ecotoxicologia.

\section{ABSTRACT \\ Persistence and leaching of simazine in soil planted with corn.}

The soil persistence and leaching of simazine were investigated under field conditions at Campinas, SP, Brazil in a loamy podzol redyellow soil planted with corn crop. Simazine was applied at the rate of $3,0 \mathrm{~kg} / \mathrm{ha}$ a.i. at preemergence of weeds and corn on january, 141992. Gas chromatography analysis of soil samples taken at five different depths $(0-10 \mathrm{~cm}, 10-20 \mathrm{~cm}$, $20-30 \mathrm{~cm}, 30-40 \mathrm{~cm}$ and $40-50 \mathrm{~cm})$, eight times after simazine application over the year showed that the highest herbicide concentration was found at the $0-10 \mathrm{~cm}$ layer; simazine residues were not found below $40 \mathrm{~cm}$ soil depth and persistence curve of the herbicide was accounted for a $3^{\text {rd. }}$ grade regression. One year after the treatment simazine residues were found in the soil $(0,08 \mathrm{mg} / \mathrm{kg})$.

Key words: Residue, soil, herbicide, ecotoxicology. 


\section{INTRODUÇÃO}

O interesse sobre os efeitos de produtos químicos sobre o meio ambiente, principalmente os agrotóxicos, teve início nos anos ses senta qu an do, então, a socied ade começou a se preocupar com os efeitos de inseticidas de uso agrícola na fauna silvestre divulgados pelo noticiário da imprensa mundial. Causou grande re pe rc us são mundial, nesta oc asião, o livro "Primavera Silenciosa" de Rachel Carson (Carson, 1964), que projetava um futuro sombrio para o planeta Terra, caso o homem não parasse de se utilizar dos agrotóxicos de um modo indiscrimina do. Recentemente, o jor nal ing lês "Daily Telegraph" incluiu o livro "Silent Spring" na lista dos dez livros que mais marcaram o século 20(5).

Com o desenvolvimento da Ecotoxicologia, ramo da ciência criada pelo Dr. Renê Thruhaut, em 1975 (Astolfi et al., 1984), os sistemas legislativos dos países procuraram estabelecer normas e mecanismos legais de uso dos agrotóxicos, bem como, provas ou testes de seu comportamento no meio ambiente, a fim de controlar de modo preventivo os riscos de contaminação decorrentes de seu uso. O objetivo final dessa legislação é definir para cada produto o perfil ec ot ox icólogico para as condições ambientais do país em que está em uso.

Um dos testes que tem contribuído para a construção do pe rfil ec ot ox icológico dos agrotóxicos são os ensaios de campo para verificar a pers istência, o acúmulo, a di ssipação e a lixiviação destes produtos no solo.

Diversos trabalhos de investigação de resíduos de agrotóxicos têm sido realizados em países desenvolvidos. Ritter (1990), em trabalho de revisão, relata que, nos Estados Unidos, mais de 70 pesticidas ja foram encontrados em água subterrânea, sendo os mais frequentes o inseticida aldicarb, o herbicida atrazina, e os fumigantes EDB, DCP e DBCP, sendo também detectada a presença de simazina.

Jornal Folha de São Paulo, p.6-2, 26/3/95
No Brasil, os trabalhos de pesquisa de herbicidas em solos de agroecossistemas são ainda em número reduzido, principal mente, qua ndo obtidos em condições naturais de cultivo. Blanco \& Oliveira (1987) relatam que a persistência de simazina, na camada de $0-10 \mathrm{~cm}$ do perfil de solo argilo so de Capivari, SP, quando aplicado em abril, foi maior que a de ametrina e atrazina, não apresentando mais bioatividade sobre a plantate ste após 11 meses da ap licação; em ou tra pesquisa (Blanco \& Oliveira, 1989), conduzida em Limeira, SP., os autores encontraram um período de 60 dias de persistência de simazina no solo para aplicação de outubro, época que corresponde ao início das chuvas no Estado. Favalessa \& Pereira (1982), em solos da Bahia, constataram por meio de bioensaios que a simazina se restringe a camada de 0-5 cm em solo barrento; traços do herbicida foram encontrados a $15-20 \mathrm{~cm}$ de profundidade, sendo que ápos 75 dias da aplicação não foram encontrados resíduos.

Assim, como contribuição ao conhecimento do perfil ecotoxicológico da simazina, um herbicida do grupo das triazinas de extenso uso na cultura do milho, foi conduzido um experimento de campo para o monitoramento de resíduos do produto durante 360 dias, até a profundidade de $50 \mathrm{~cm}$ do perfil do solo.

\section{MATERIAL E MÉTODOS}

\section{Ensaio de campo}

O experimento foi conduzido na Estação Experimental de Campinas, Seção de Herbicidas, Instituto Biológico, Campinas, SP, 22 ${ }^{\circ} 54^{\prime}$ latitude Sul, 4704' longitude Oeste e $693 \mathrm{~m}$ de altitude. O solo do experimento foi um podzol vermelhoamarelo com as características físico-químicas descritas na Tabela 1.

O terreno de plantio foi preparado por meio de uma aração com arado de disco, seguidas de uma gradagem com grade nivela dora de 28 discos.

Omilho, var. AG 401 foi plantado em 13 de janeiro de 1992, em sulcos espaçados de Im, com 8 plantas por metro linear. A adubação 
foi realizada com $400 \mathrm{~kg} / \mathrm{ha}$ da fórmula 4-14-8, na linha de plantio, complementada com uma adubação de cobertura de $20,0 \mathrm{~kg} / \mathrm{ha}$ com sulfato de amônio, aos 42 dias da germinação do milho.

TABELA 1. Características físicas e químicas do perfil do solo onde foi conduzido o experimento.*

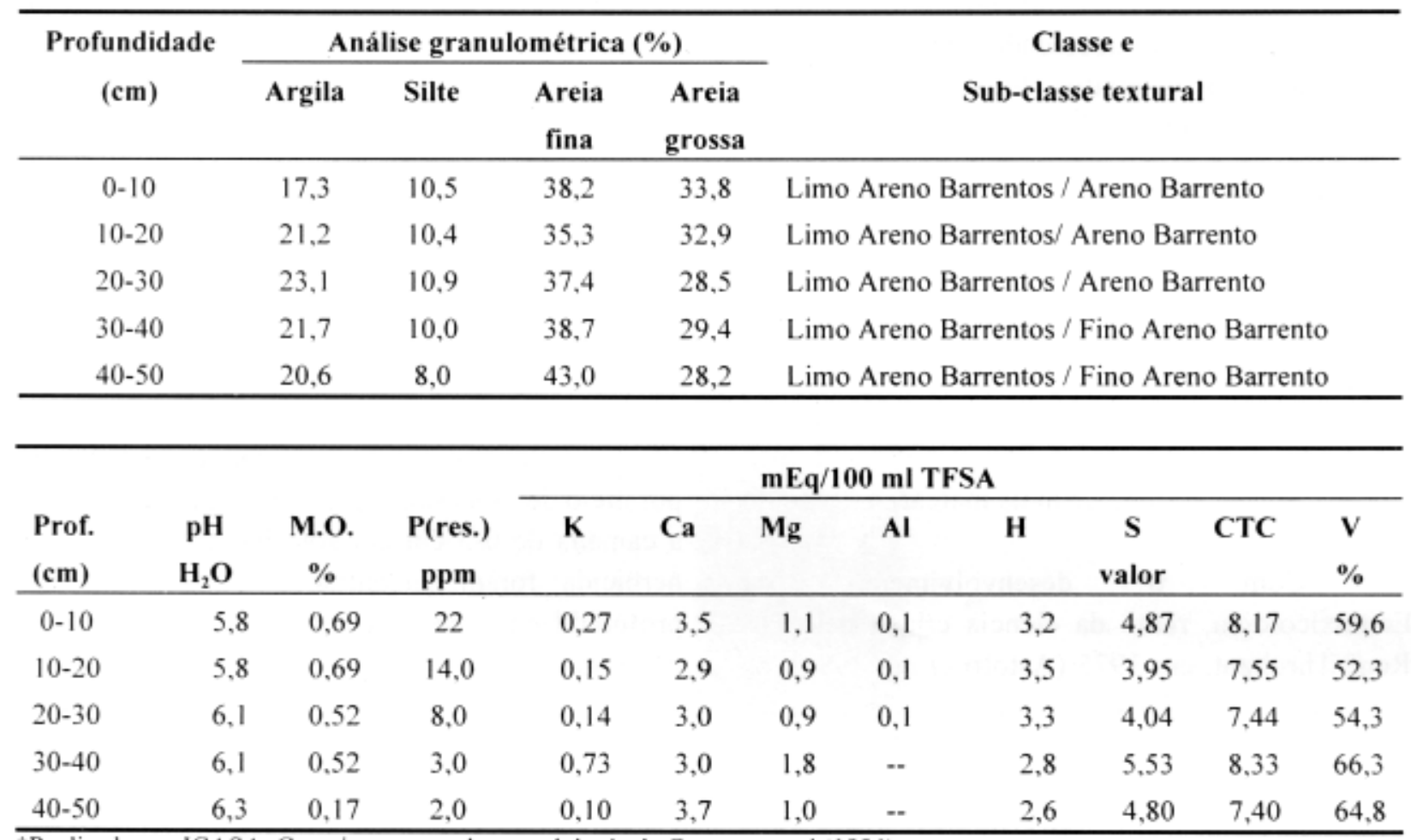

"Realizadas no ICASA, Campinas, segundo metodologia de Camargo et al (1986).

A simazina na dose de $3,0 \mathrm{~kg} / \mathrm{ha}$ i.a. foi aplicada em área total, em 14 de janeiro de 1992, um dia após o plantio do mi lho e em préemergência das plantas daninhas. Empre gou-se 6,0 1/ha de Gesatop 500 Ciba-Geigy, formulado como solução concentrada conten do $500 \mathrm{~g}$ de simazina por litro.

Utilizou-se um pulverizador costal, à pressão constante fornecida por $\mathrm{CO}^{2}\left(30 \mathrm{Ib} / \mathrm{pol}_{2}\right)$, com barra de quatro bicos 1004, projetando uma faixa de aplicação de $2,5 \mathrm{~m}$, na vazão de 300 1/ha. Por ocasião da aplicação o solo apre sentava-se com $11 \%$ de umidade, e as condições climáticas foram: $25^{\circ} \mathrm{C}$ de temperatura do ar, $83 \%$ de umidade relativa do ar e vento a $2,20 \mathrm{~km} / \mathrm{h}$.

Como tratamento controle (teste em branco), para verificar a existência de resíduos de simazina no local, foram retiradas 10 amostras de terra/profundidade da área experimental, dois dias antes da aplicação do herbicida, nas profundidades de 0-10, 10-20, 20-30, 30-40 e 40-50 cm.

$\mathrm{O}$ delineamento experimental adotado foi o de blocos ao acaso, num esquema fatorial com 8 "épocas de amostragem" X 5 "profundidades de amostragem", com quatro repetições. As épocas de amostragem for am: 0 dia ( $\log 0$ após a aplicação), 14 dias após o tratamento (DAT), 37 DAT, 65 DAT, 100 DAT, 127 DAT, 183 DAT e 360 DAT; como profundidade de coleta das amos tras foram adotados cinco faixas: 0-10, 1020, 20-30, 30-40 e 40-50 cm.

Todo o perímetro da área experimental foi margeado por uma faixa de $2 \mathrm{~m}$ de largura onde também foi aplicado o herbicida para evitar movimento lateral do produto de dentro para fora. 
Os blocos foram constituídos de 12 linhas de milho com 5 metros, cada bloco com $60 \mathrm{~m} 2$, sendo as oito entrelinhas centrais casualizadas como parcelas ex perimentais (épocas de amostrage m de solo). Para cada época foram coletadas cinco sub amostras de terra, utilizandose um trado tipo meia-cana, de aço inoxidável, 2,3 $\mathrm{cm}$ de diâmetro por $60 \mathrm{~cm}$ de comprimento, graduado com subdivisões de $10 \mathrm{~cm}$. A terra das cinco sub amostras/parcela de cada época foi misturada de acordo com a faixa de profundidade e a ordem de cada bloco, resultando em uma amostra/profundidade/época/parcela. Para os procedimentos analíticos o material do Bloco I foi reunido ao do Bloco III e o do Bloco II com o do Bloco IV, reduzindo-se assim para duas amostras compostas de terra/profundidade/época. Foram ut ilizados para possíve is ex plicações do comportamento do herbicida no solo os dados climáticos da estação meteorólogica da Estação Ex pe ri mental do Institu to Agronô mi co de Campinas, localizada cerca de $7 \mathrm{~km}$ do local do experimento.

\section{An ál is e de resíd uos}

As amostras de solo permaneceram armazenadas à temperatura de $15^{\circ} \mathrm{C}$ negativos até a execução das análises quando foram secas à temperatura ambiente, moídas e peneiradas em malha de $0,2 \mathrm{~mm}$ (TFSA).

O métod o utilizado para a determinação de resíduos foi o descrito por Ramsteiner et al. (1974), para multiresíduos de triazinas em água, solo e plantas.

Para a análise foram retiradas 25 a $30 \mathrm{~g}$ de solo seco, adicionando-se $20 \%$ do peso em água e $100 \mathrm{~m} 1$ de metanol como extrator, permanecendo a amostra em refluxo a quente por duas horas.

Após filtração, transferiu-se, à temperatura ambiente, o extrato total para um funil de separação de $500 \mathrm{~m} 1$, diluindo com $100 \mathrm{~m} 1$ de água, e adicionando-se $20 \mathrm{~m} 1$ de solução saturada de cloreto de sódio.
A partição líquido-líquido foi feita com duas vezes $100 \mathrm{ml}$ de cloreto de metileno. Os extratos em cloreto de metileno foram filtrados através de sulfato de sódio anidro e recolhidos juntos em um balão de fundo redondo de $250 \mathrm{~m} 1$, evaporado e o resídu o remane scente rediluido em $5 \mathrm{mI}$ de tolueno e levado a purificação em coluna de alumina básica desativada ao grau de ativid ade $\mathrm{V}$.

A coluna de purificação, de dimensões de $2 \mathrm{~mm}$ (diâmetro interno) por $200 \mathrm{~mm}$ (comprimento), foi empacotada com cerca de $25 \mathrm{~g}$ de alumina básica grau $\mathrm{V}$, obtendo-se uma coluna de $7 \mathrm{~cm}$ de altura.

$\mathrm{O}$ extrato em tolueno foi transferido para a coluna, lavado com $80 \mathrm{~m} 1$ de n-hexano, e eluido com $75 \mathrm{~m} 1$ de mistura de $\mathrm{n}$-hexano e éter dietílico na proporção de 2:1 obtendo-se um eluato recolhido em balão de fundo redondo de $100 \mathrm{~m} 1$ evaporado até a secura. O resíduo foi rediluido em volume conhecido da mistura de $n$ hexano e etanol absoluto 1:1, formando uma solução usada para a quantificação.

A quantificação foi feita usando-se um cromatógrafo gasoso Hewlett-Packard, modelo 5890, série I, equipad o com detect or termoiônico específico para Nitrogênio e Fósforo - NPD; utilizando-se coluna de vidro de $1,8 \mathrm{~m}$ de comprimento por $2 \mathrm{~mm}$ de diâmetro interno, empacotada com Carbowax 20M 3\% sobre GasChrom Q 80-100\#.

As condições analíticas de temperatura foram: coluna $200^{\circ} \mathrm{C}$; injetor, $220^{\circ} \mathrm{C}$; detector, $250^{\circ} \mathrm{C}$. Os fluxos de gases foram: Nitrogênio, $30,0 \mathrm{~m} 1 /$ minuto; Hidrogên io, 3,50m1/minuto; ar sintético, 110,0m1/minuto; tempo de retenção de 4,6 minutos. O limite mínimo de determinação foi de $0,05 \mathrm{mg} / \mathrm{kg}$ de solo, com recuperação do ativo tolerada pela variação do método analítico de $95 \%$ a $115 \%$.

Por meio de três diferentes soluções padrão de simazina, injetadas a períodos prédeterminados em uma série de amostras, foi 
calculada a curva de calibração do produto por regressão logaritma dupla, sendo utilizada na determinação da concentração de simazina nesta série de amostras.

Os resultados analíticos foram submetidos a análise de regressão polinomial em função das épocas de amostragem.

\section{RESULTADOS E DISCUSSÃO}

Os resultados analíticos para simazina no teste em branco não revelaram presença do herbicida em quaisquer das faixas de profundidade do solo antes da instalação do experimento (teste em branco).

Os dados analíticos após a aplicação de simazina são apresentados na Tabela 2 , em valores médios de resíduos nas profundidades de $0-10,10$ 20, 20-30, 30-40 e 40-50 cm, monitora dos logo após a aplic ação e aos 14, 37, 65, 100, 127, 183 e 360 dias após o tratamento (DAT). A Tabela 2 apresenta, também, os valores residuais totais, bem como os remanescentes e dissipação da simazina em função do tempo na faixa de $0-10 \mathrm{~cm}$.

TABELA 2. Valores médios de resíduos de simazina em $\mathrm{mg} / \mathrm{kg}$ de solo em função da profundidade do solo e época de amostragem.

\begin{tabular}{|c|c|c|c|c|c|c|c|c|}
\hline \multirow{2}{*}{$\begin{array}{c}\text { Época de } \\
\text { amostragem } \\
\text { Dias após o } \\
\text { tratamento }\end{array}$} & \multicolumn{5}{|c|}{$\begin{array}{c}\text { Profundidade } \\
(\mathrm{cm})\end{array}$} & \multirow{2}{*}{$\begin{array}{l}\text { Total } \\
\mathrm{mg} / \mathrm{kg}\end{array}$} & \multicolumn{2}{|c|}{$\begin{array}{l}\text { Residuo } \\
0-10 \mathrm{~cm}\end{array}$} \\
\hline & $0-10$ & $10-20$ & $20-30$ & $30-40$ & $40-50$ & & $\begin{array}{c}\text { remanescente* } \\
\% \\
\end{array}$ & $\begin{array}{c}\text { Dissipação* } \\
\% \\
\end{array}$ \\
\hline 0 & 2.500 & n.d. & n.d. & n.d. & n.d. & 2,500 & 100,00 & 0,0 \\
\hline 14 & 1.515 & 0.525 & 0.140 & 0.055 & n.d. & 2.235 & 60,60 & 39.40 \\
\hline 37 & 1.045 & 0.205 & 0.060 & n.d. & n.d. & 1.310 & 41,80 & 58,20 \\
\hline 65 & 0,540 & 0,165 & 0,080 & 0.060 & n.d. & 0.803 & 21.60 & 78,40 \\
\hline 100 & 0.390 & 0.165 & n.d. & n.d. & n.d. & 0.555 & 15.60 & 84,40 \\
\hline 127 & 0.205 & 0,050 & n.d. & n.d. & n.d. & 0,255 & 8.20 & 91.80 \\
\hline 183 & 0.230 & 0.055 & n.d. & n.d. & n.d. & 0.258 & 8,12 & 90,80 \\
\hline 360 & 0,080 & n.d. & n.d. & n.d. & n.d. & 0,080 & 3,20 & 96,80 \\
\hline
\end{tabular}

n.d.: nào detectável, isto é. abaixo do limite de detecçâo (0.05 mg/kg de solo): * em função a 0 DAT

Análise de regressão para a profundidade de 0-10 cm (Resumo).

Persistência:

\begin{tabular}{lcccc}
\hline \multicolumn{1}{c}{ F.V. } & GL & SQ & F & R2 \\
\hline Regressão & 3 & 9,05 & $98,50^{* *}$ & 0,99 \\
Residuo & 4 & 0,12 & & \\
\hline Total & 7 & 9,17 & & \\
\hline ** significativo a 1\% de probabilidade & &
\end{tabular}

Inicialmente, observa-se que a maior concentração de simazina permanece na camada de $0-10 \mathrm{~cm}$ do solo. Em camadas mais profundas o produto foi encontrado na faixa de $30-40 \mathrm{~cm}$ aos 14 e 65 DAT, porém em níveis bem próximos ao
Dissipação:

\begin{tabular}{clcc}
\hline GL & \multicolumn{1}{c}{ SQ } & F & R2 \\
\hline 1 & 0,0002 & $332,36^{* *}$ & 0,99 \\
5 & $3,01.10-6$ & & \\
\hline 6 & 0,0002 & & \\
\hline
\end{tabular}

limite de detecção $(0,05 \mathrm{mg} / \mathrm{kg}$ de solo). A partir de 100 dias simazina não foi mais encontrada nesta camada nem na profundidade de $20-30 \mathrm{~cm}$. Na faixa de $0-10 \mathrm{~cm}$ simazina permaneceu até 360 DAT, em concentração próxima do limite de

Planta Daninha, v. 15, n. 2, 1997. 
detecção. Na profundidade de $10-20 \mathrm{~cm}$, simazina persistiu em níveis ainda altos até 100 DAT; após esta data (127 e 183 DAT), foram encontrados resíduos praticamente igua is ao limite de detecção do método utilizado.

Considerando -se a camada de $0-10 \mathrm{~cm}$ como representativa do comportamento da simazina no solo, onde ocorreu a maior concentração e persistência da molécula, pode-se construir as curvas de persistência e dissipação do produto através da análise de regressão dos dados analíticos (Tabela 2).

Pelo gráfico de persistência (Figura 2), observa-se que o nível residual de simazina decresce rapidamente, e após 130 DAT tende a estabilidade até 230 DAT, quando novamente há uma tendên cia de redução até 360 DAT. Isto pode ser explicado, pela distribuição das chuvas (Figura 1), onde se observa um período de estiagem de 112 DAT a 215 DAT, o que proporcionaria uma condição adversa ao desenvolvimento de microrganismos e uma maior adsorção da molécula, tornando mais difícil sua disponibilidade, e por conseguinte uma menor dissipação; após os 230 DAT, as chuvas frequentes favoreceriam a dissipação por agentes bióticos, além do que com o aumento da umidade do solo a dessorção seria favorecida tornando a molécula disponível a este tipo de dissip ação.

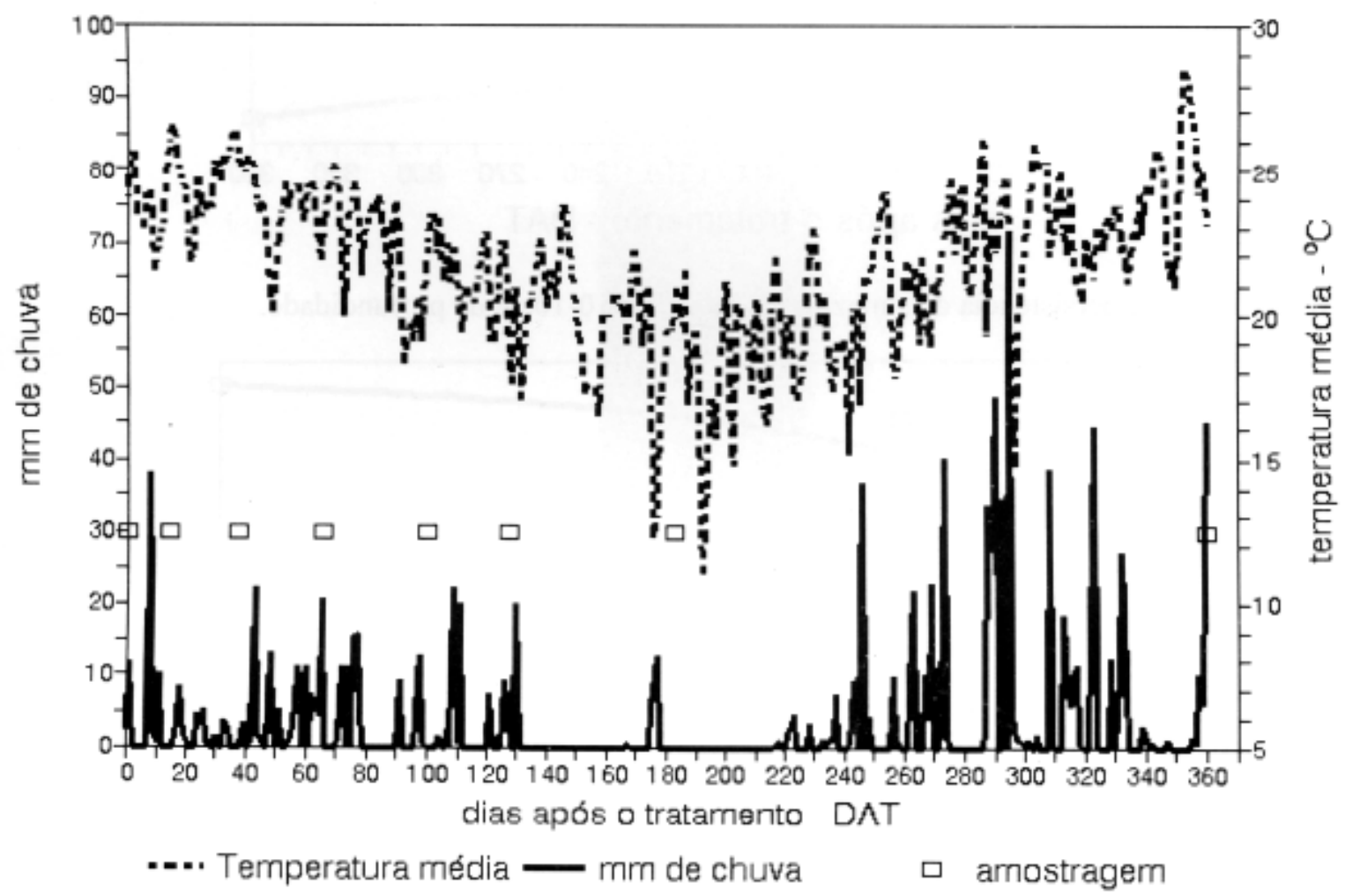

FIGURA 1. Dados pluvio métric os diários e temperatu ra média diária no períod o de con dução do experimento (14/01/1992 a 08/01/1993).

Na curva de diss ipação (Fig ura 3), complementar à Figura 2, o modelo matemático demonstra uma rápida taxa de porcentagem de dissipação, em função do nível inicial (0 DAT), passando a estabilidade após os 130 DAT. O regime hídrico também explicaria este comportamento, sendo a meia-vida inicial calculada pelo modelo matemático de 22 dias. A variação da temperatura média diária (Figura 1), aparentemente não influiu na dissipação. 
Persistência e lixiviação do herbicida simazina em solo barrento cultivado com milho.

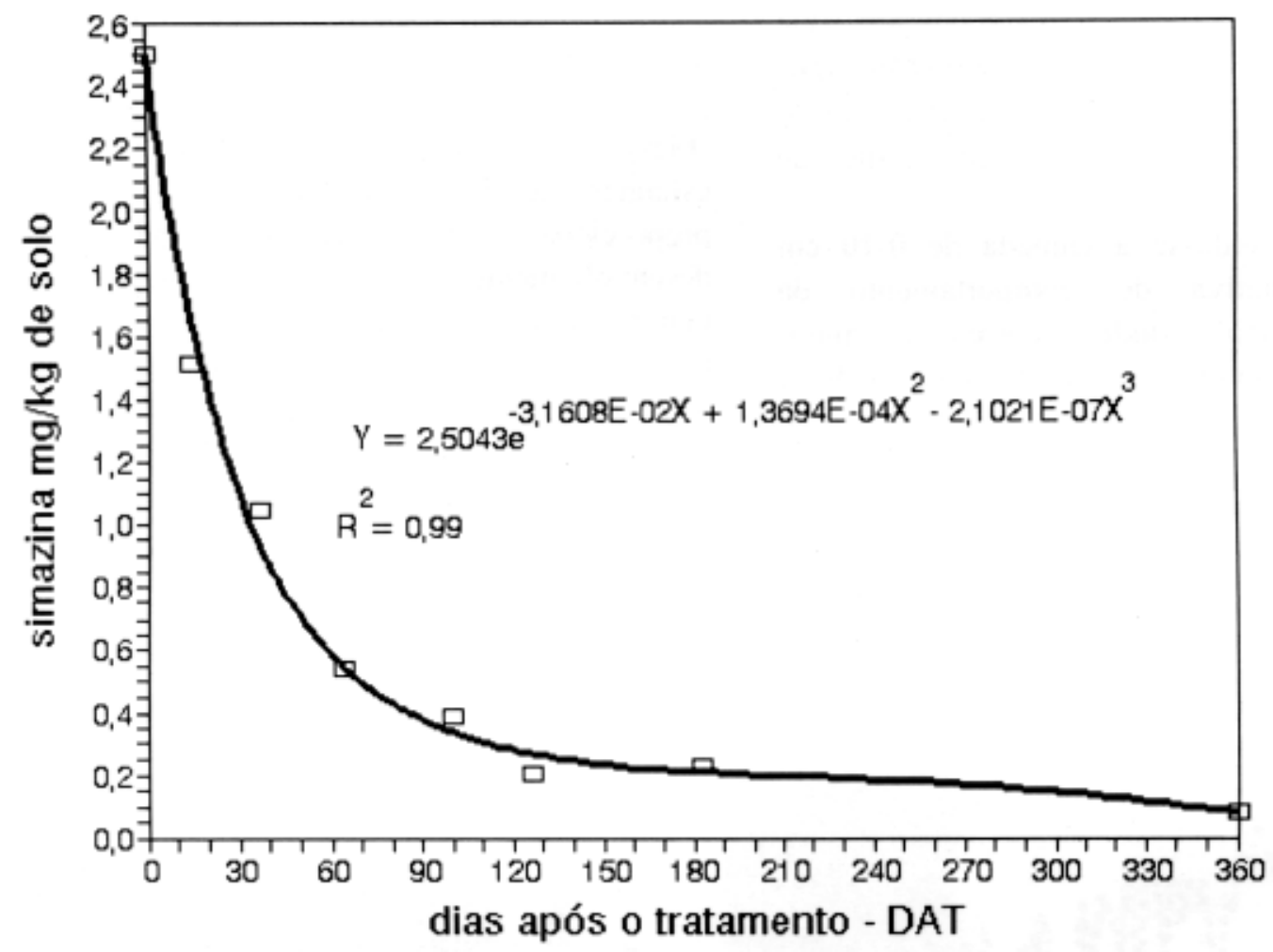

FIGURA 2. Curva de persistência de simazina na camada de $0-10 \mathrm{~cm}$ de profundidade.

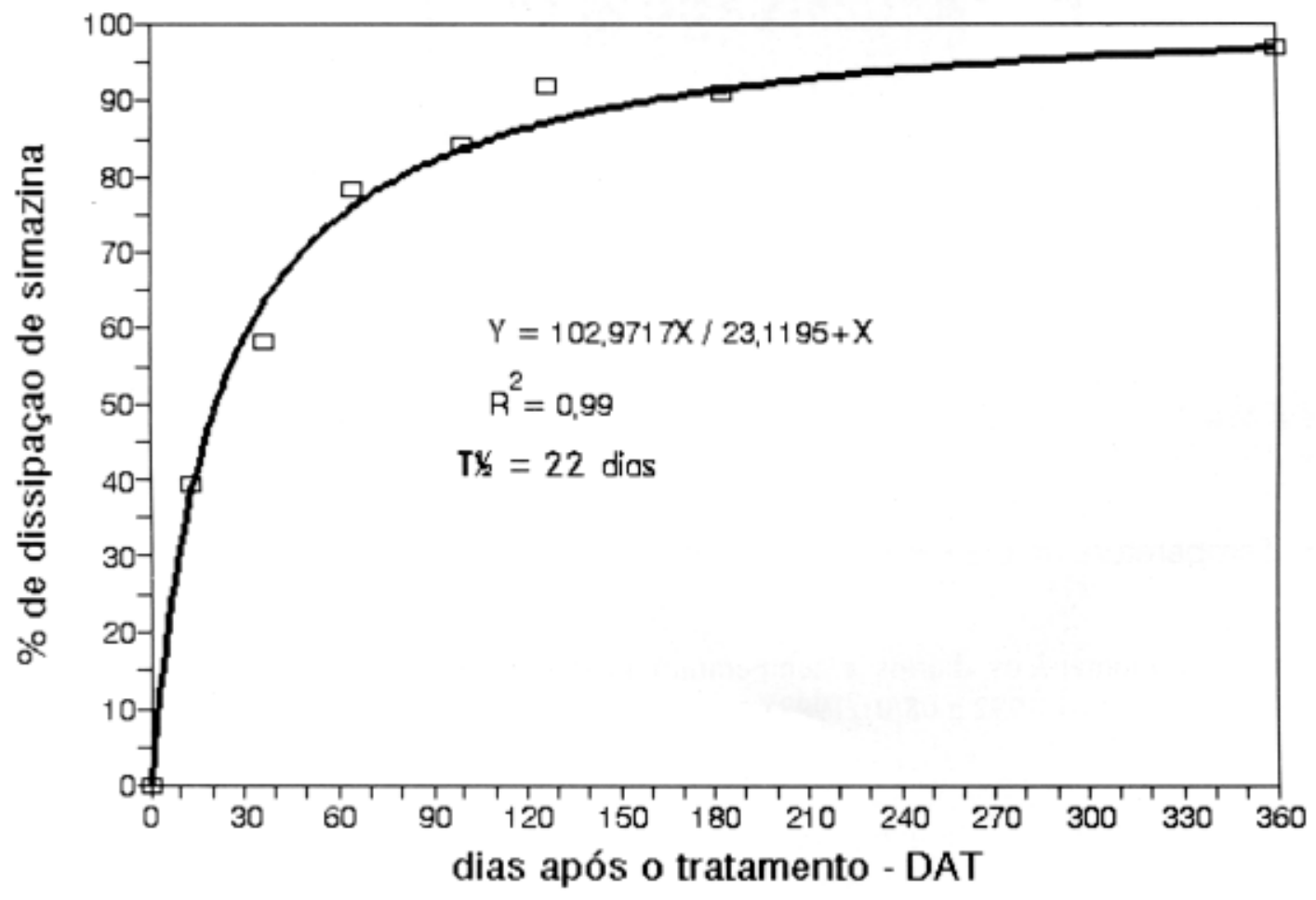

FIGURA 3. Curva de dissipação de simazina na faixa de profundidade de 0-10cm em relação ao nível inicial (ODAT). 
A Figura 4, derivada da Figura 2, representa a velocidade de dissipação diária, em porcentagem, em função do resíduo inicial de cada dia. Neste gráfico, observa-se que a velocidade de dissipação diária não foi constante em função do tempo, mas diretamente proporcional ao regime hídrico. A velocidade de dissipação, alta no início, estabilizou-se em um ní vel baix o $(>0,25 \%)$ no período de ba ix a pluviosidade, voltando a crescer com o início das chuvas, e al cançando o índice de $1,5 \%$ de dissipação diária aos 360 DAT.

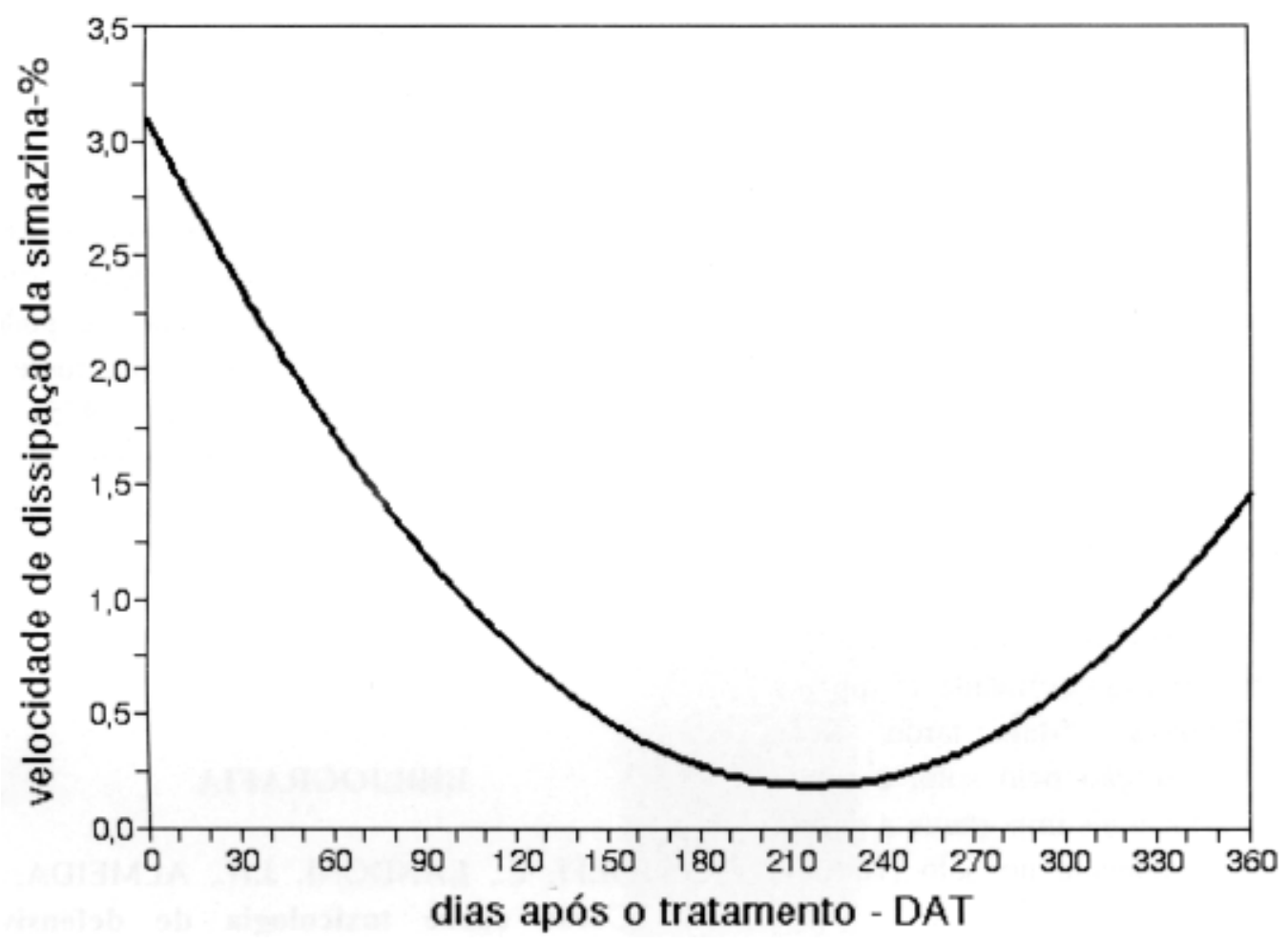

FIGURA 4. Velocidade diária de dissipação de simazine, em porcentagem, em função da concentração de cada dia.

Os resultados relatados por Blanco \& Oliveira (1987) sobre a falta de bioatividade residual de simazina após 11 meses da sua aplicação em abril, de certo modo, apesar de se rem me to dologias diferentes, são mu ito semelhantes aos aqui descritos, pois, a concentração de $0,08 \mathrm{mg}$ de simazina/kg de solo aos 360 DAT é tão baixa que possivelmente não deverá provocar redução biológica em plantas sensíveis.

Se forem consideradas as quantidades de simazina encontradas na camada de $30-40 \mathrm{~cm}$, 0,055 e $0,060 \mathrm{mg}$ aos 14 e 65 DAT, respectivamente, como inexpressivas, pode-se considerar, também, que a lixiviação da simazina no solo foi moderada. Valores residuais expressivos foram encontrados em profundidades de até $30 \mathrm{~cm}$.

Os resultados relatados por Favalessa \& Pereira (1982), em solos da Bahia, se guem a mesma tendência quanto ao comportamento da simazina, isto é, pequena lixiviação e concentração na camada superficial do solo. Koehler (1983), em uma plantação de Pinus, em Michigan, EUA, constatou que 120 dias após o tratamen to com simazina, apenas $1,5 \%$ do composto permanece no solo à profundidade de 0 $7 \mathrm{~cm}$; foram encontrados resíduos até $7-14 \mathrm{~cm}$ de profundidade.

Estes resultados, de certo modo, diferem 
dos encontrados por pesquisadores em condições estrangeiras.

Harrys et al. (1968), citados por Helling (1970), concluem que as s-triazinas são praticamente imóveis no solo. Outras referências tende $m$ a confirmar este fato para a simazina (Bouchet, 1967; Burnside et al., 1961; Clay \& Mckone, 1968; Dawson et al., 1968; Kozlowski \& Kuntz, 1963; Kozaczenko, 1966; Sheets, 19'59).

No entanto, tal generalização deve ser balanceada pelas condições do solo, da molécula do grupo das triazinas e do clima em que são obtidos os resultados. Daws on et al. (1986) encontraram simazina um ano após a última aplicação anual, de um total de seis, na profundidade de 10 a $20 \mathrm{~cm}$; Albers \& Homburg (1959), citados por Sheets (1970), também, encontraram movimento de simazina abaixo de 15 $\mathrm{cm}$ no período de seis meses em vários solos.

A retenção das triazinas nas camadas superficiais do perfil do solo, inicialmente, foi atribuida a sua pequena solubilidade ( $5 \mathrm{ppm}$ a $20{ }^{\circ} \mathrm{C}$ para a simazina). Ma is tarde, fico $u$ reconhecido que a adsorção pelo solo, e não a insolubilidade, é o fator mais importante a definir a moviment ação da molécula no solo (Hartley, 1976).

Se relacionarmos o índice $\mathrm{pH}$ da solução do solo, com o pk $\left(21^{\circ} \mathrm{C}\right)$ da simazina igual a 1,7 , verifica-se que apesar de ser uma base fraca, praticamente ela não se ioniza (em média $0,006 \%$ de ionização de todas as moléculas), comportando-se como um composto molecular. Se gundo Briggs (1981, 1984), a si mazina apresenta $\log$ Kow $=1,51$ o que lhe confere um carater lipofílico, sendo adsorvida principalmente pela matéria orgânica e pelos colóides do solo. Assim, a mobilidade das triazinas aumenta quando a matéria orgânica diminui (Sheets, 1970). Gast (1959), citado por Helling (1970), demonstrou a mobilidade da simazina em colunas em diferentes solos, em relação ao conteúdo de matéria orgânica não encontrando movimento em solos com 27 a $30 \%$ M.O. e movimento até $17,50 \mathrm{~cm}$ em solos arenosos. Em experimentos de campo Burnside et al. (1963) encontraram maiores concentrações de simazi na abaix o de $30 \mathrm{~cm}$ que nos $15 \mathrm{~cm}$ acima, 16 meses após a aplicação.

Os resultados encontrados por esses autores e o baixo teor de M. O. do solo (Tabela 1) explicaria a lixiviação da simazina até a camada mais profunda do perfil do solo $(40 \mathrm{~cm})$.

Sabe-se que as condições edafoclimáticas alteram a persistência dos herbicidas no solo, de modo direto ou por seus efeitos no modelo de de grad ação, se ja el a bi ót ic a, ca us ad a por microrganismos, ou abiótica.

A inativação das s-triazinas está geralmente, correlacionado com condições ótimas de crescimento dos microrganismos que podem utilizar a molécula do herbicida como fonte de Carbono e Nitrogênio (Esser et al., 1975). No entanto vários fatores como aumento de temperatura e umidade do solo, índice $\mathrm{pH}$ baixo e al ta taxa de matéria or gâni ca favorecem a degradação das clorotriazinas por hidrólise (Esser et al., 1975).

\section{BIBLIOGRAFIA}

ASTOLFI, E., LANDONI, J.H., ALMEIDA, E. Curso sobre toxicologia de defensivos agrícolas, 3.ed. São Paulo. ANDEF, 1984. $159 \mathrm{p}$.

BLANCO, H.G., OLIVEIRA, D.A. Persi stência de ametrine, atrazine, simazina e diuron no solo após aplicações anuais, em culturas de can a-de-açuc ar. Pesqui. Agro pecu. Bras., v.24, n.9, p.1161-68, 1989.

BLANCO, H.G., OLIVEIRA, D.A. Persi stên cia de herbicidas em latossolo vermelho-amarelo em cultura de cana-de-açúcar. Pesqui. Agropecu. Bras., v.22, n.7, p.681-87, 1987.

BOUCHET, F. Estude de l'influence de la nature $\mathrm{du}$ sol sur l'action herbicide de la simazine. Weed Res., v.7, p.102-16, 1967.

BRIGGS, G.G. Factores affecting the uptake of 
soil-applied chemicals by plants and other organisms. British Crop Protection Conference. 1984. Proceedings. p.35-47.

BRIGGS, G.G. Theoretical and experimental relationships between soil adsorption, octanol - water partition coefficients, water solubilities, bioconcentration factors, and the parachor. J. Agric. Food Chem., v.29, p.1050-59, 1981.

BURNSIDE, O.C., FENSTER, C.R., WICKS, G.A. Dissipation and leaching of monuron, simazine, and atrazine in Nebraska soils. Weeds, v.11, p.209-13, 1963.

BURNSIDE, O.C., SCHMIDT, E.L., BEHRENS, R. Dissipation of simazine, from the soils. Weeds, v.9. p.477-84, 1961.

CAMARGO, O.A. Métodos de análise química, mineralógica e física de solos do Instituto Agronômico de Campinas, IAC, 1986. 94 p. (Boletim Técnico n.106).

CARSON, R. Primavera silenciosa. São Paulo: Melhoramentos, 1964. 305p.

CLAY. D.V., MCKONE, C.E. The persistence of chlorthiamid, lenacil and simazine in uncropped soil. British Weed Control Conference, 9, Brigthon, England, 1968. Proceedings, v.2, p.933-938.

DAWSON, J.H., BRUNS, V.F., CLORE, W.J. Residual monuron, diuron and simazine in a vineyard soil. Weed Sci., v.16, p.63-65, 1968.

ESSER, H.O., DUPUIS, G., EBERT, E., VOGEL, C., MARCO, G.J. S-triazines. In: P.C. Kearney \& D.D.Kaufamn, ed. Herbicides: Chemistry, Degradation and Mode of Action, v.1, 2.ed., .N.Y, 1975. p.129-208.
FAVALESSA, O., PEREIRA, R.C. Lixiviação e persistência dos herbicidas diuron e simazine em solos da Bahia, Brasil. In: CONGRESSO BRASILEIRO DE HERBICIDAS, 14. \& CONGRESSO DE LA ASOCIACION LATINOAMERICANA DE MALEZAS, 6. Resumos... Campinas: 1982. p.28

HARTLEY, G.S. Physical behaviour in the soil. In: AUDUS, L.J., ed. Herbicides, v.2. London, Academic Press, 1976. p.1-26.

HELLING, G.S. Movement of s-triazine herbicides in soils. Residue Ver., v.32, p.175-210, 1970.

KOEHLER, C.W. Persistên cia de simazina no solo, aplicada para controlar vegetação herbácea em plantio florestal. Revista do Setor de Ciências Agrarias. v.5, n.1/2, p.4953, 1983.

KOZACZENKO, $H$. Factores affecting the efficiency of herbicides. Biul. Warzyw. v.8, n.31 (1965). Apud. Weed Abstracts, 15, 1966. 1780.

KOZLOWSKI, T.T., KUNTZ, J.E. Effects of simazine, atrazine, propazine, and Eptan on growth and developement of pine seedlings.

Soil Sci., v.95, n.164, 1963.

RAMSTEINER, K., HÜR MANN, W.D., OBERLE, D.O. Multiresidue method for the determination of triazine herbicides in fieldgrown agricultural crops, water and soils. J. AOAC, v.57, n.1, p.192-201, 1974.

RITTER, W. F. Pesticide contamination of ground water in the United States - a review. J. Environ. Sci. Health Part B, Pestic., Food Contam., Agric. Wastes, v.25, n.1, p.1-29, 1990. 
SHEETS, T.J. Persistence of triazine herbicides in soils. Residue Rev., v.32, p. 287-310, 1970.
SHEETS, T.J. The comparative toxicities of monuron and simazine in soil. Weeds, v.7, p.189-219, 1959. 